\title{
ADVANCED SEAL RIG EXPERIMENTS AND ANALYSIS
}

Roger Paolillo

Pratt \& Whitney

East Hartford, Connecticut

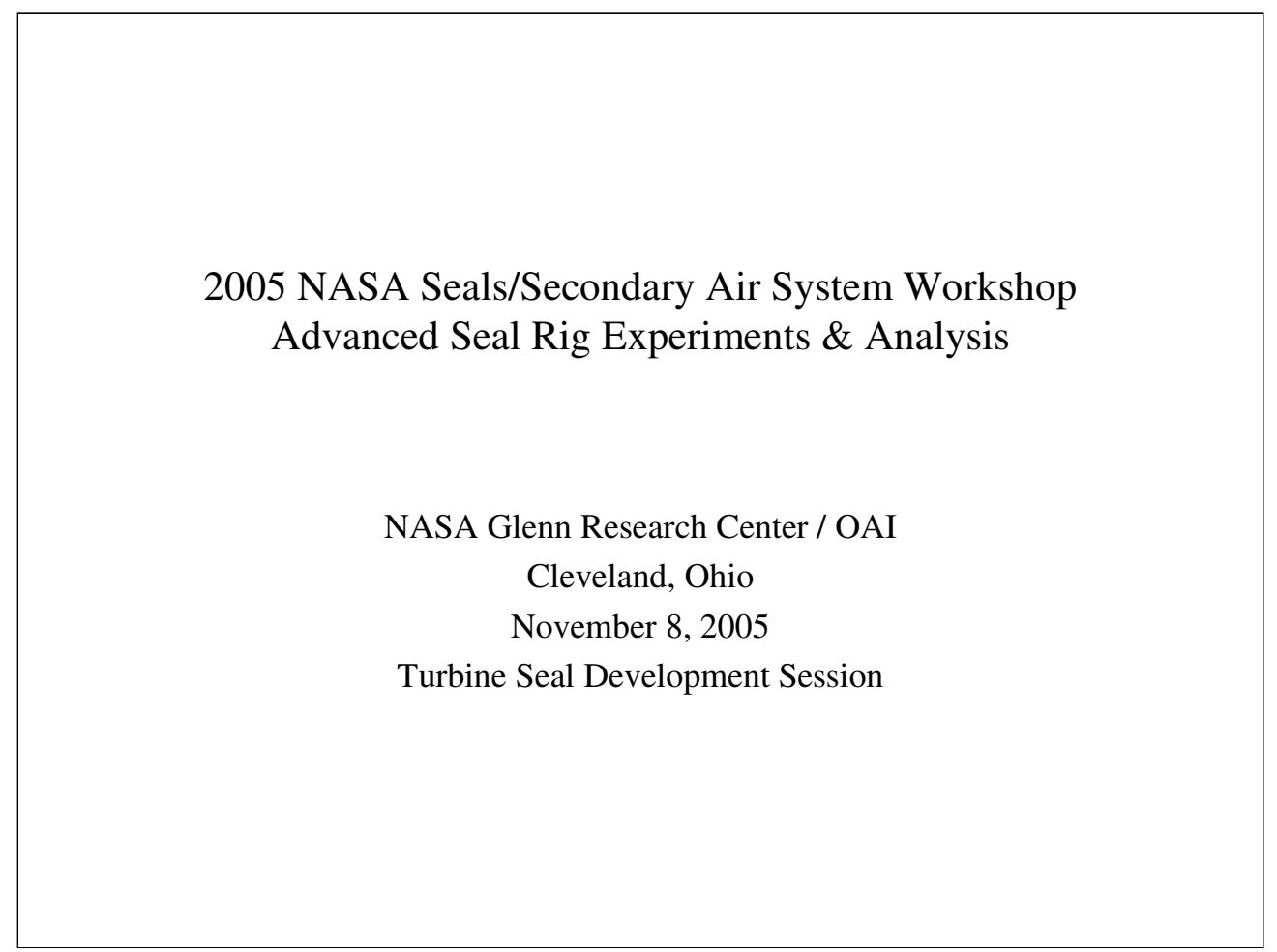


2005 NASA Seals/Secondary Air System Workshop Advanced Seal Rig Experiments \& Analysis

Topics for Discussion

- Advanced Sealing

- Compliant

- Non-Contact

- Labyrinth seals

- Labyrinth Seals in Gas Turbines

- Typical lab seal design parameters

Typical flow parameter correlation based on available empirical rig data

- CFD: Labyrinth Seal Physics Based Models

- Validated with available empirical rig data

- Evaluate additional geometric effects through sensitivity analyses

Evaluate additional aerodynamic effects through sensitivity analyse

- $\quad$ ASR rig

- Tri-party agreement offers a win-win-win situation

- Rig capabilities simulate engine operating conditions of surface speed, temperature, and pressure level

Accurate measurements of clearance and measured seal flow

- Test Articles

- How related to analysis work

How modified for rig

- Test Results

- Concave seal

- Hammerhead seal

- Conclusions/Future Work 


\section{NASA Seals/Secondary Air System Workshop}

Advanced Seal Rig Experiments \& Analysis

Rotating Seal options: Why Still Work On Labyrinth Seals

- Compliant Seals eg. Brush Seals, Finger Seals

- 3-5X flow reduction

- developing higher surface speed, temperature, and pressure levels

- interference/debris/durability issues

- Non Contact Seals eg. Aspirating, Film Riding

- 5-10X flow reduction but still improving surface speed, temperature, and delta pressure levels

- limited applications

- interference issues

- Labyrinth Seals still the workhorse seal in gas turbine engines

- long history of use in compressors, turbines, around bearing compartments

- cheaper to make than many other seals

- small improvement $x$ many seals (up to 50*) = big gain in performance/operability

- well and still investigated by academia $\&$ industry

- with a proper abradable seal land can handle interference

*NASA/TM 2004-211991/Part 1 "Turbomachine Sealing and Secondary Flows"

R, C. Hendricks, B. M. Steinetz and M. J. Braun

Why still work to reduce leakage of of labyrinth seals.

Still the workhorse seal in gas turbines 


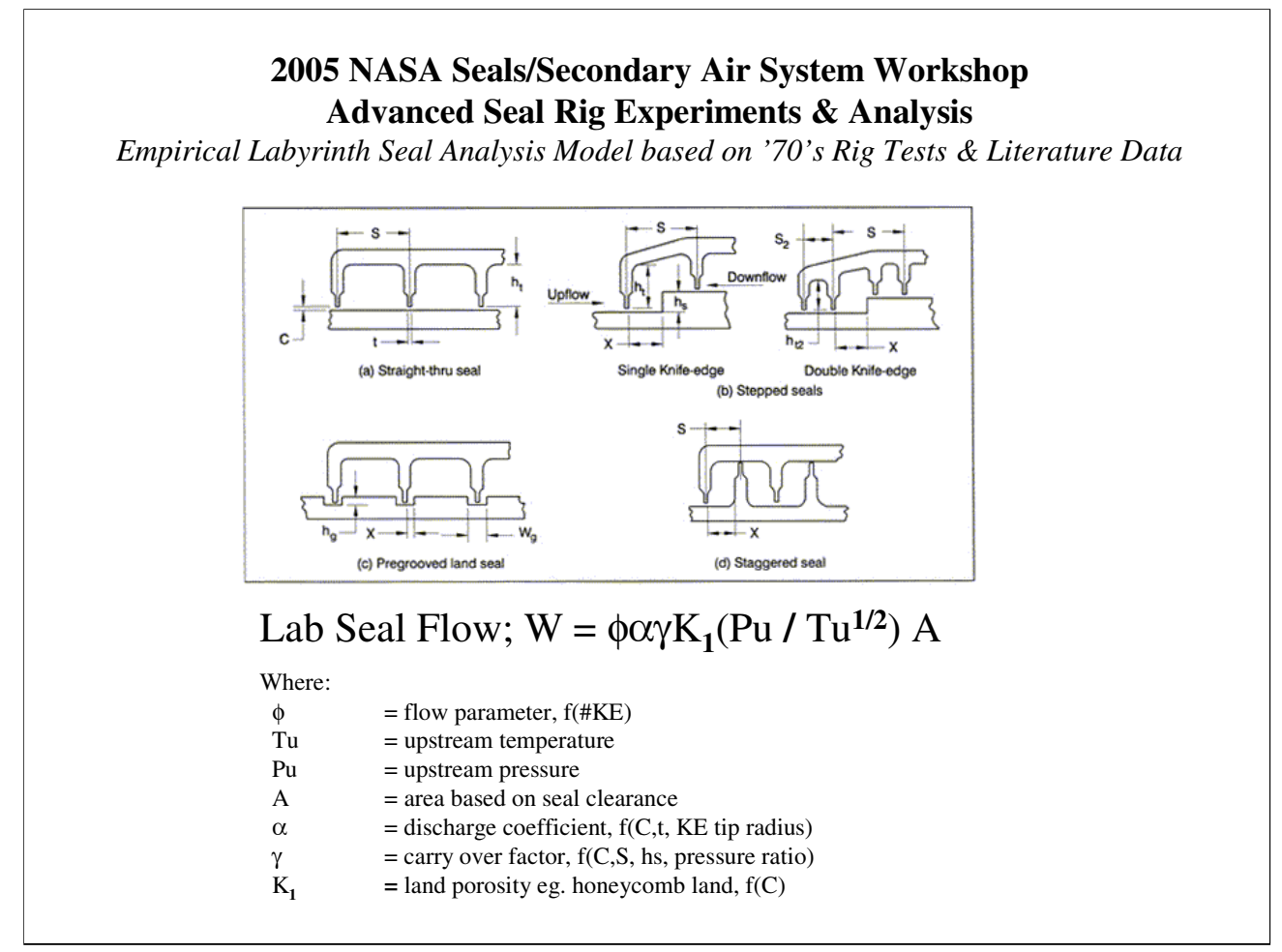

Labyrinth seal design system based on seal's leakage from the early '70's from gas turbine engine testing and rig testing

All empirically developed design systems 


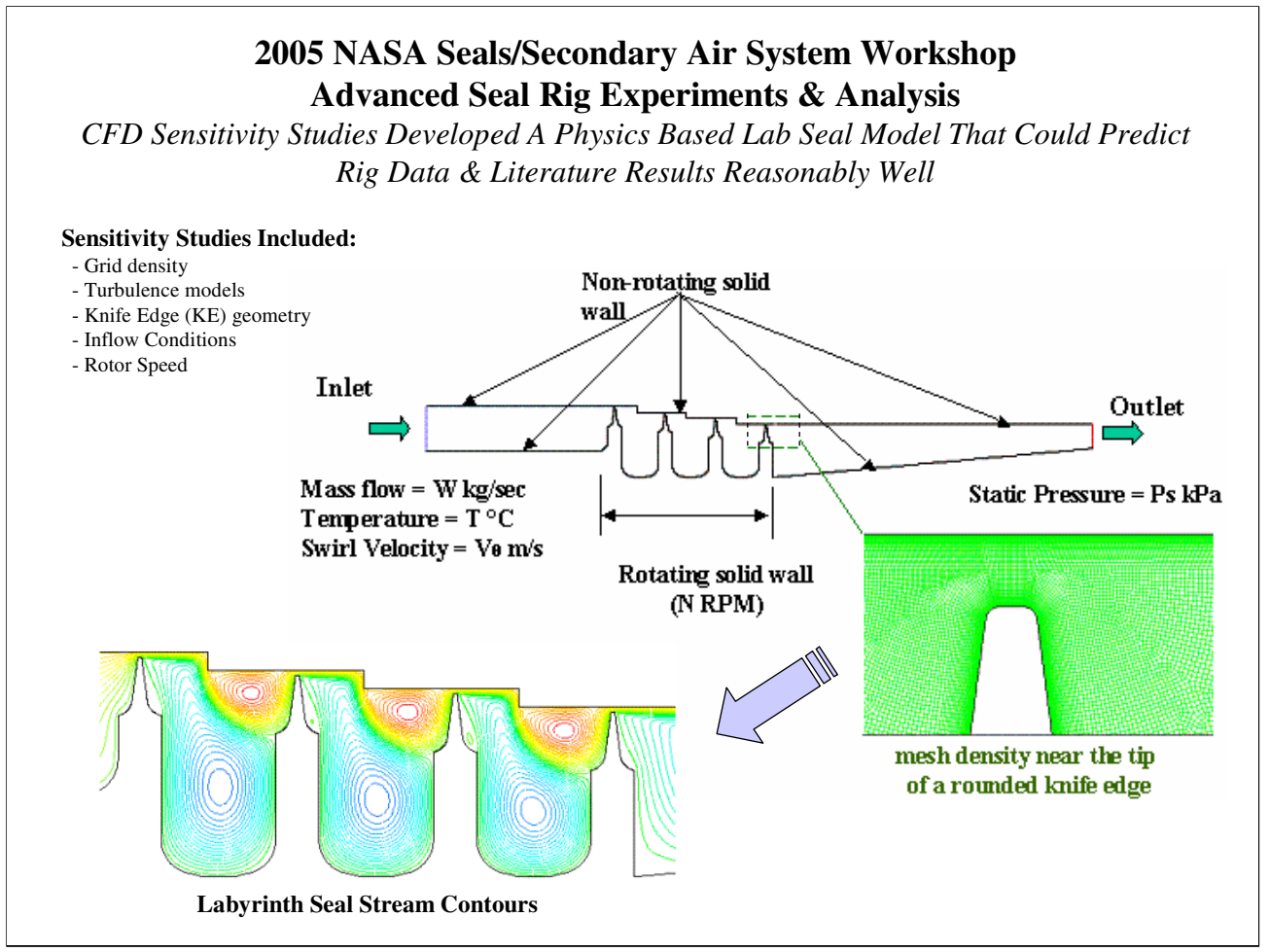

Advent of CFD maturity has provided a physics based modeling approach to assessing seal leakage

The CFD models must be first validated with the available test data before these seal models can be used to explore leakage reduction designs. 


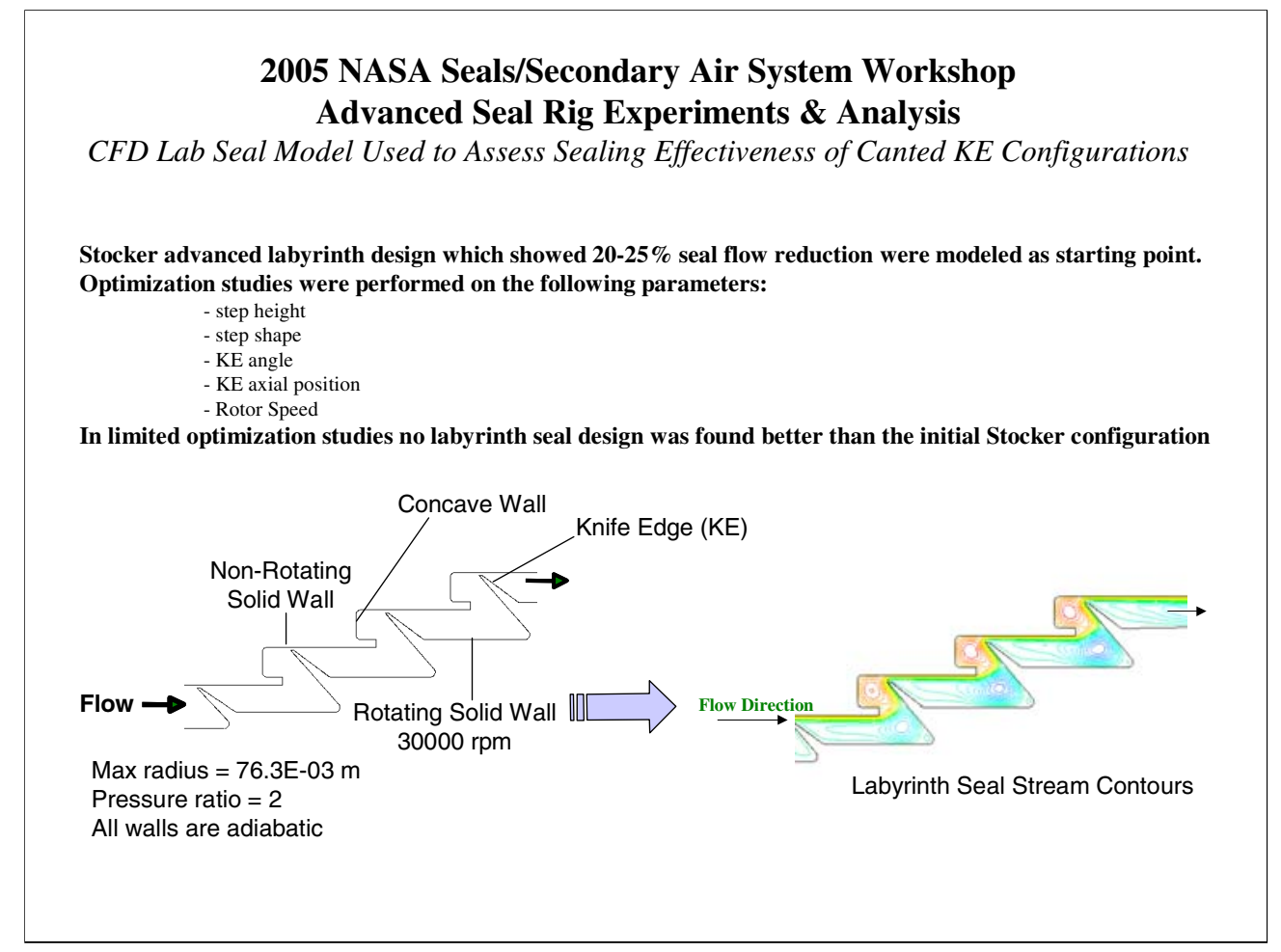

Best leakage reduction concepts found in the literature are evaluated with validated CFD models 2D axisymmetric CFD models sensitivity studies did not improve upon existing design concepts 


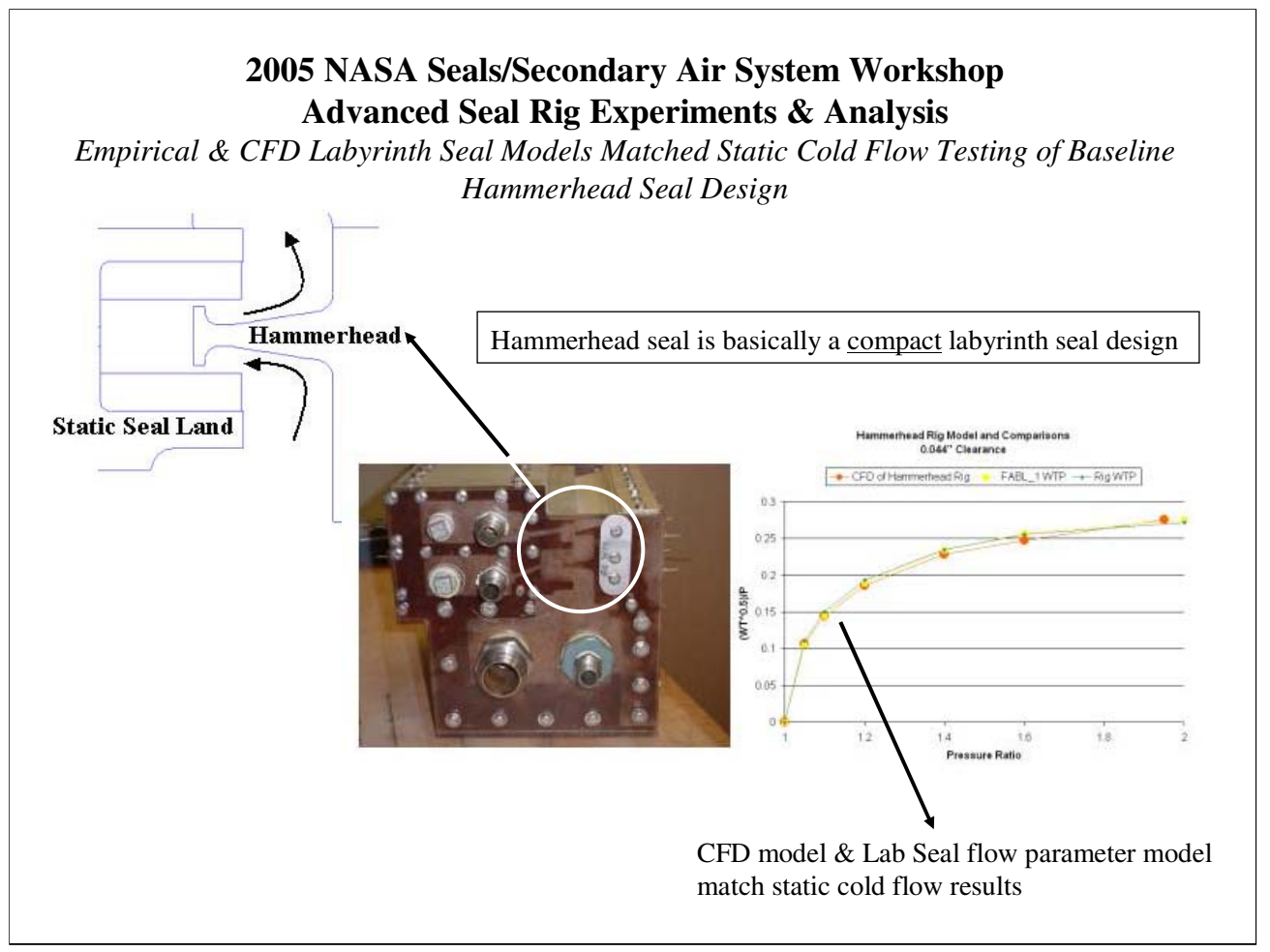

The hammerhead seal design is an attempt to minimize the geometric design space needed for multiple knife edged labyrinth seals

The hammerhead seal design also attempts to maintain a tight clearance for one set of knife edges at all times of gas turbine engine operation

Initially the seal is modeled as a conventional labyrinth seal of the same number of knife edges. Static cold flow tests confirm this modeling approach. 


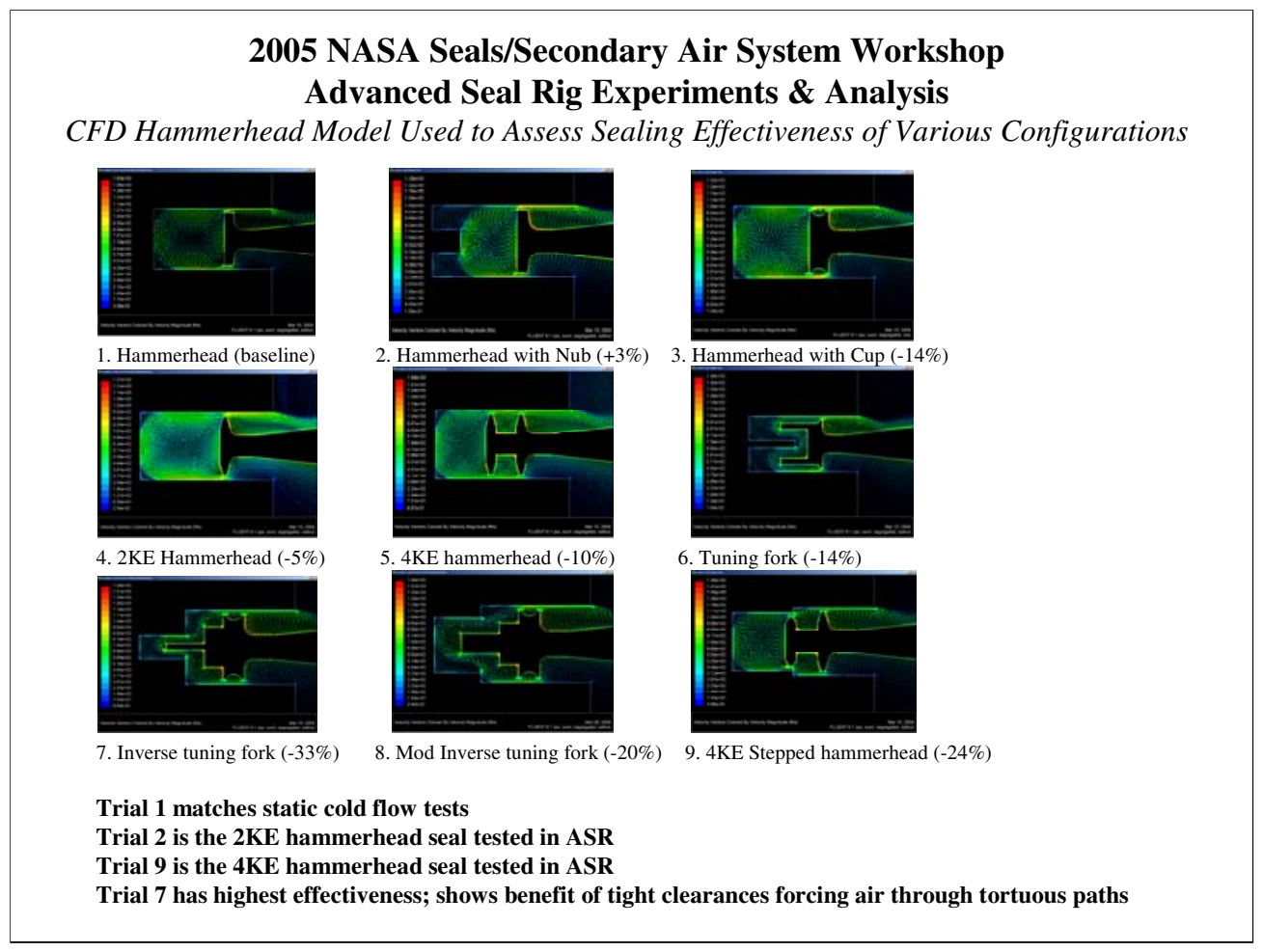

CFD modeling is used as an analytical test tool to explore best leakage design concepts

As expected, if it behaves like a labyrinth seal then the same leakage reduction features work best (more knife edges, stepped seal lands) 


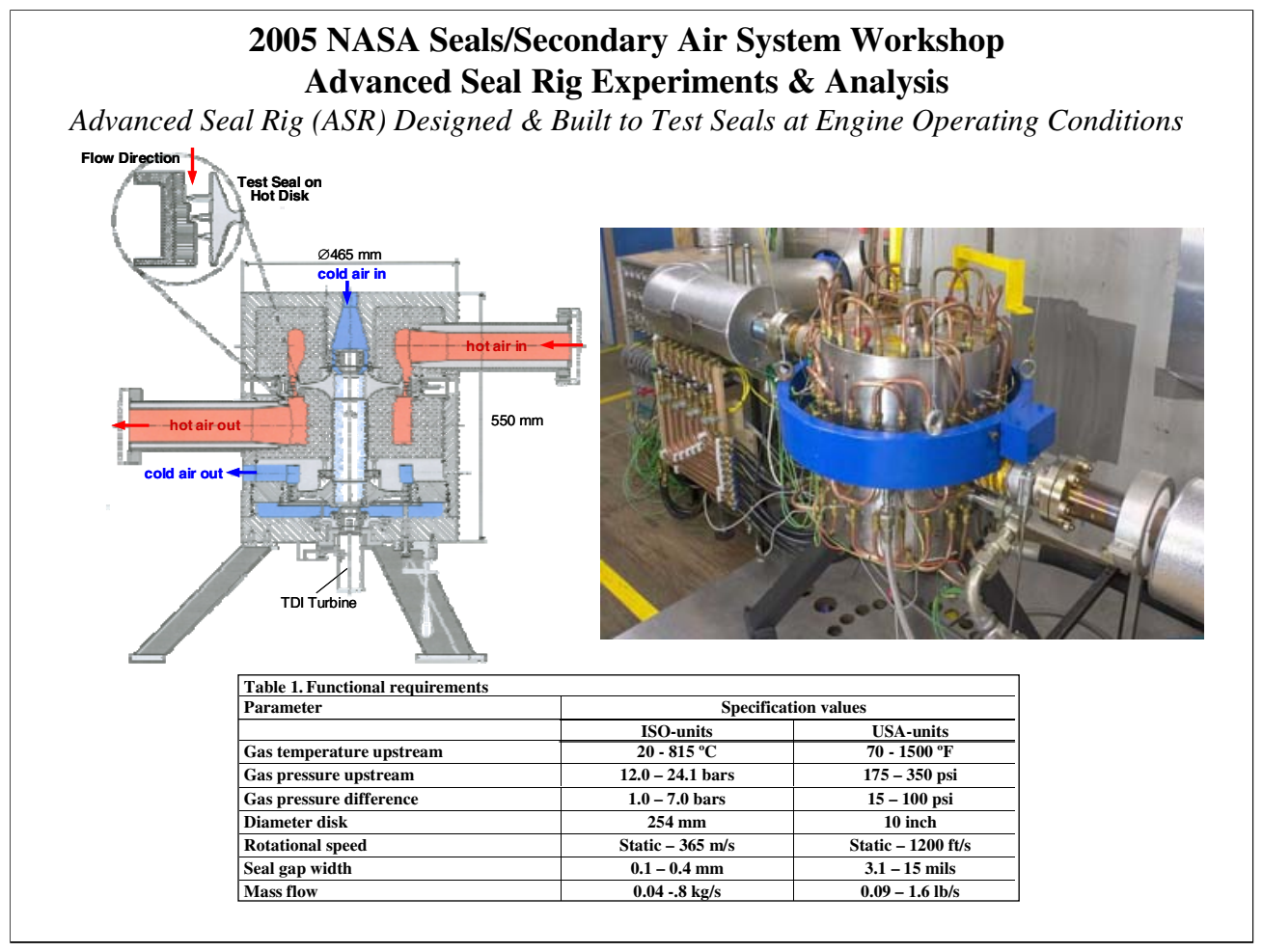

Rig developed at the National Aerospace Laboratory (NLR) in The Netherlands to test advanced seal concepts at near gas turbine engine operating conditions. 


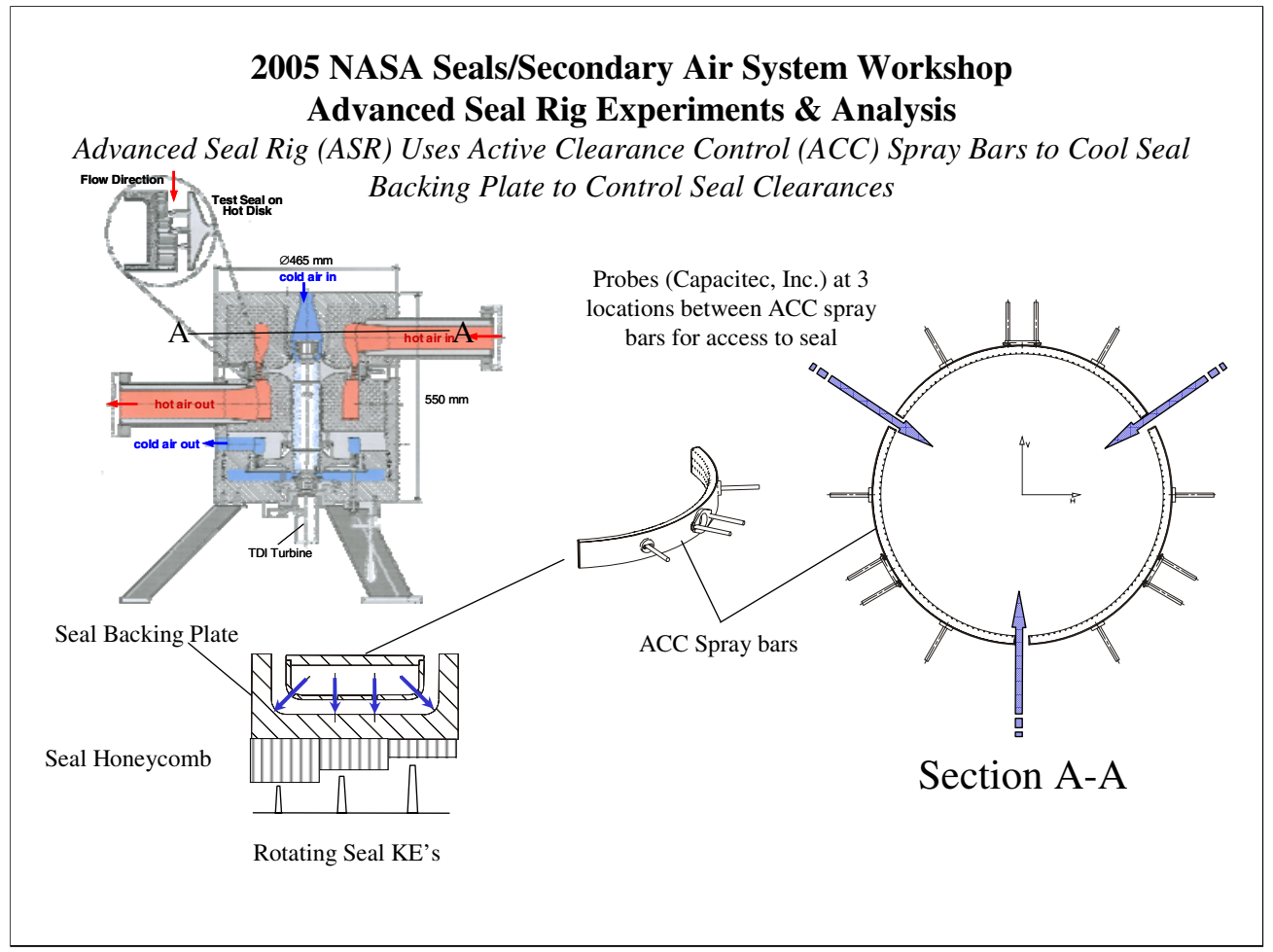

A clearance control design feature utilizes external spray bars to impinge cold shop air on the outer diameter of the test seal static backing plate to radially move the test seal land inward to the desired seal clearance.

Three equally circumferentially spaced probes (Capacitec, Inc.) are installed measure seal clearance and determine the level of active clearance control air needed. 


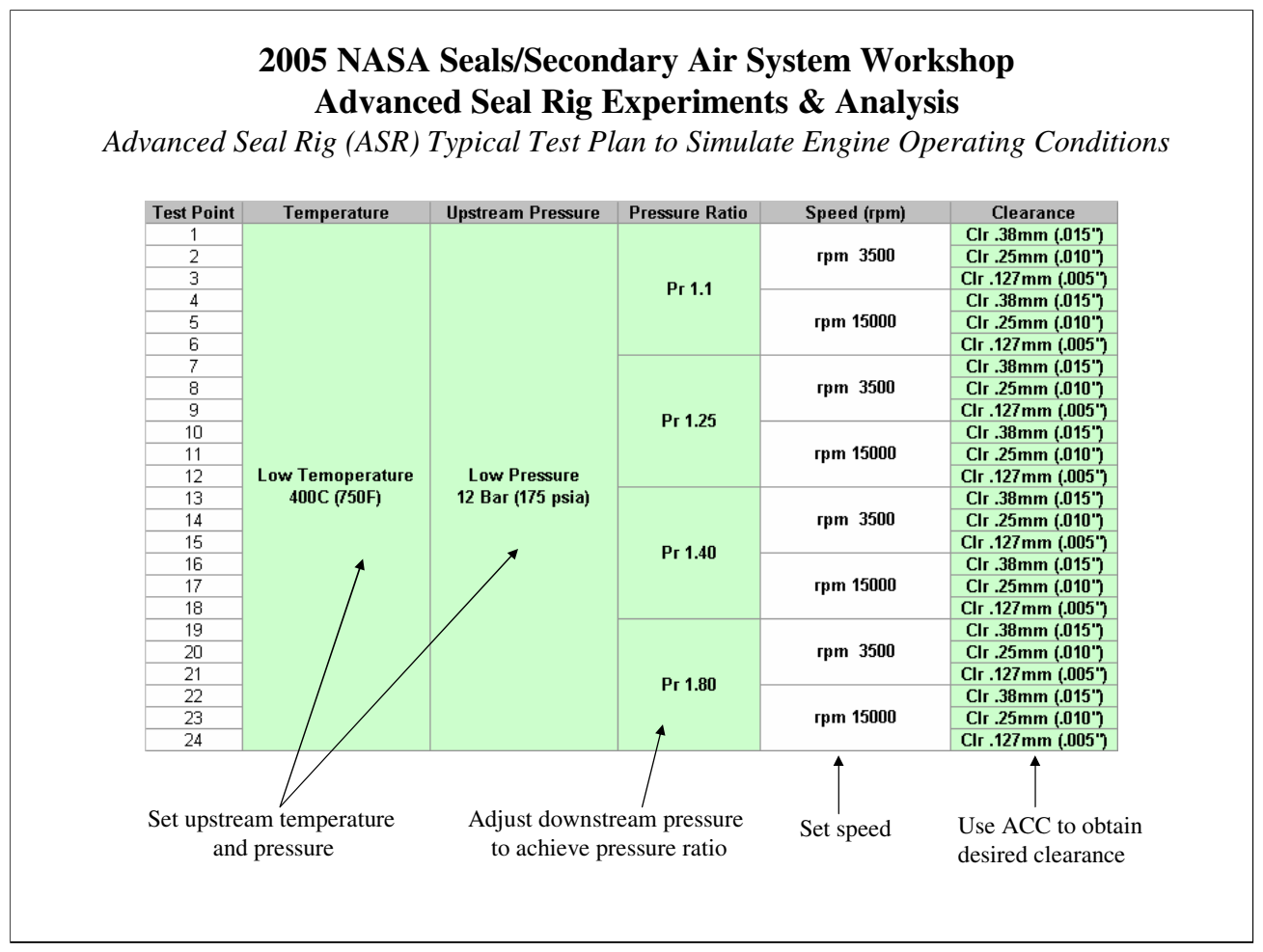

The seal rig can independently vary temperature, pressure, pressure ratio, speed, and seal clearance. 


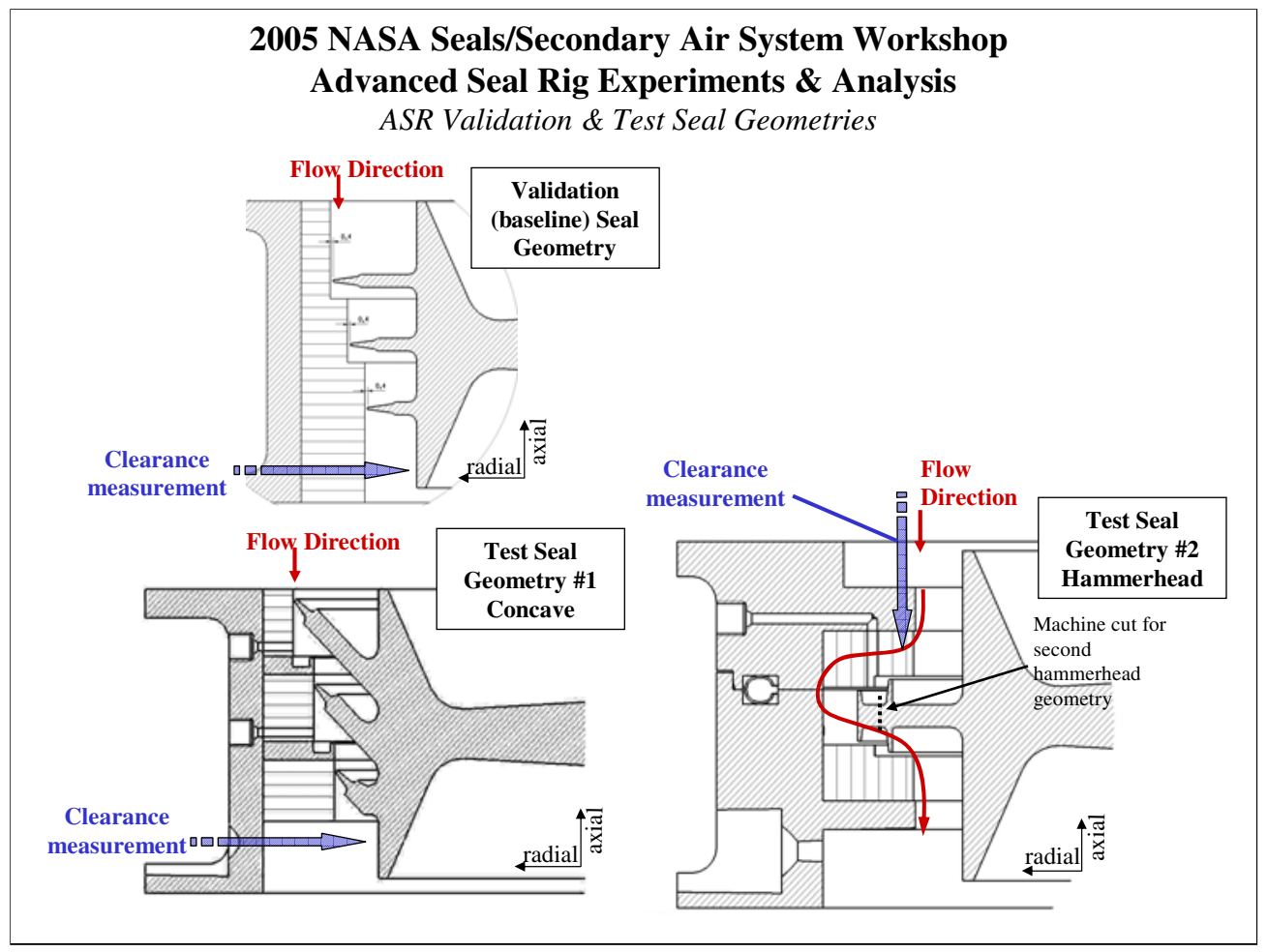

The baseline seal geometry was used to validate the rig. The baseline seal is a standard $3 \mathrm{knife}$ edge stepped seal configuration that is typically found in many gas turbine engines.

Rig data matched within 10\% the lab seal design predictions (AIAA-2005-3092).

The advanced lab seal design test results would then be assessed against both the existing lab seal design system predictions and against the baseline seal data. 


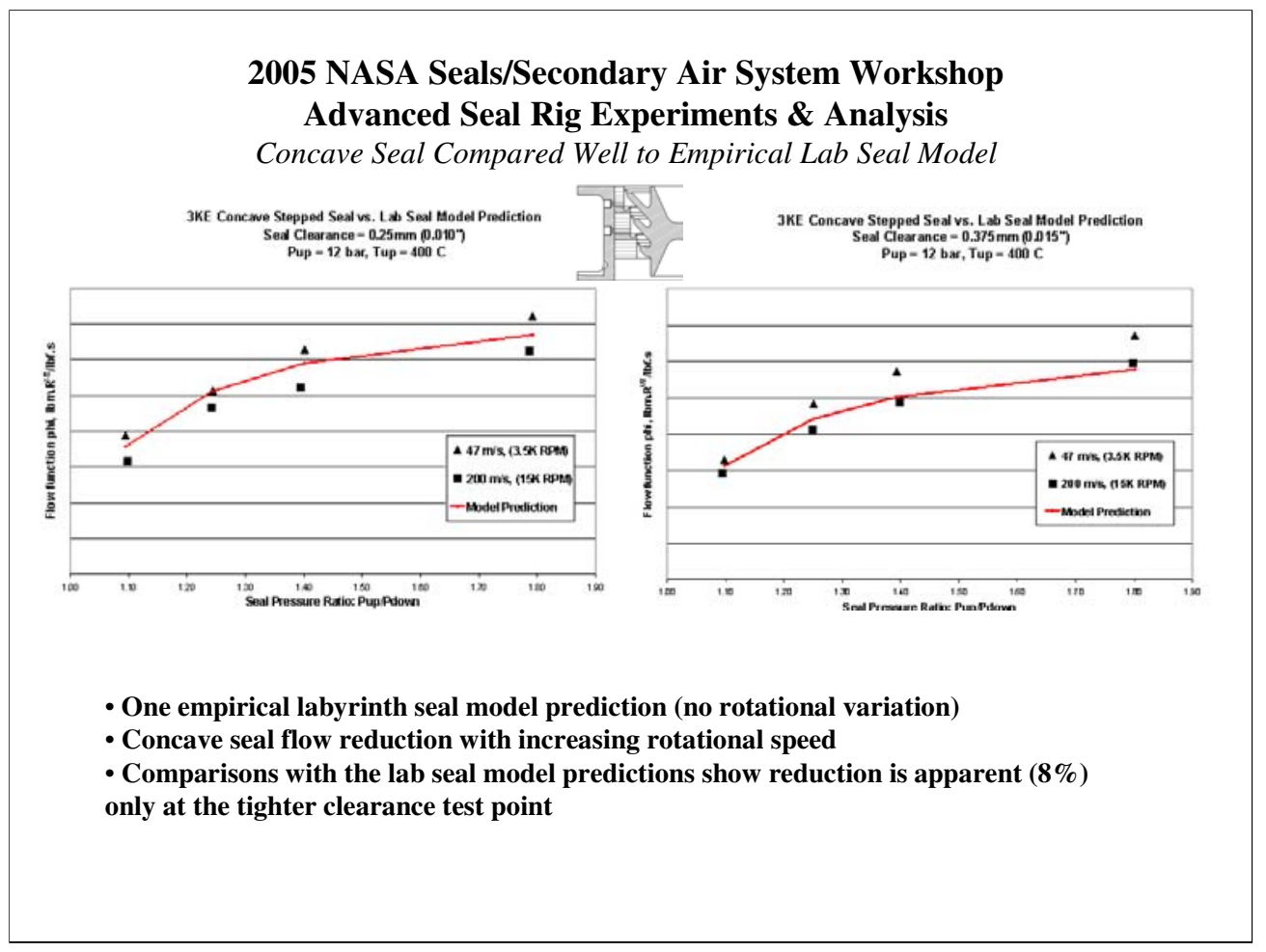

Concave seal test data compared well with the lab seal design system predictions. 


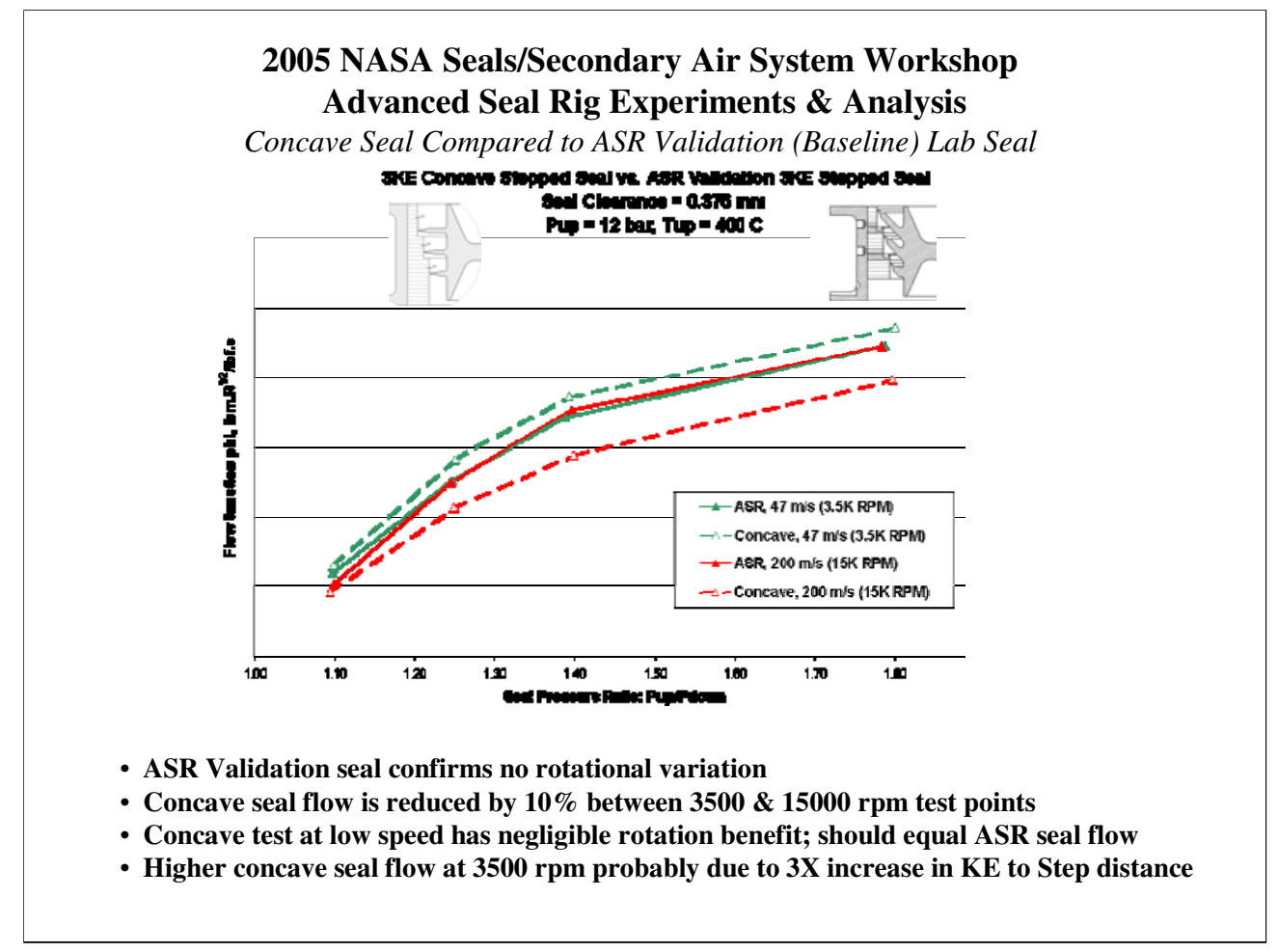

Concave seal test data compared to baseline seal clearly shows a rotational effect that reduces seal leakage. 


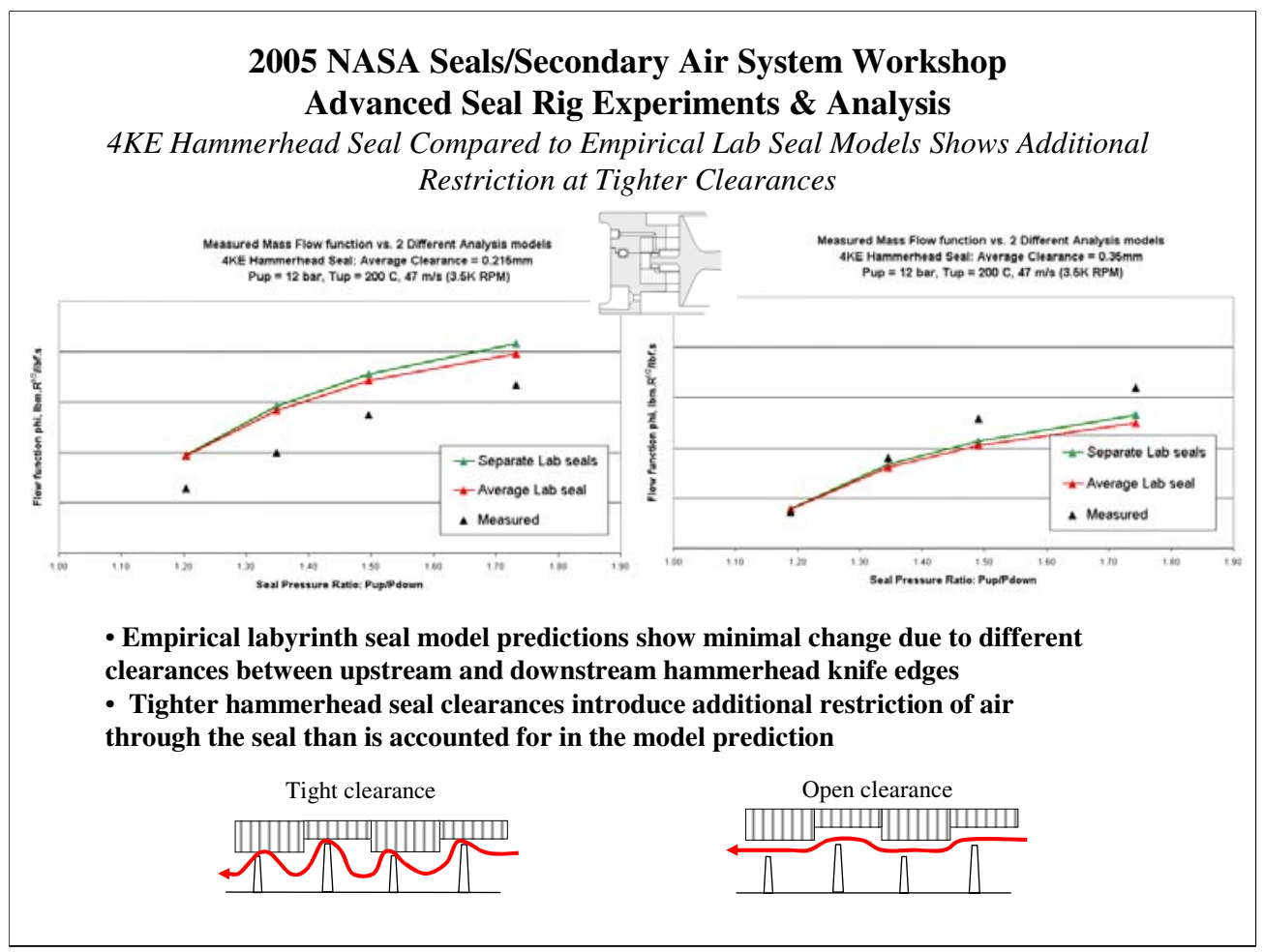

4KE Hammerhead seal compared to empirical design system labyrinth seal model (4 knife edge stepped seal) shows additional restriction effect at the tighter clearances test condition.

"Stretching out" hammerhead seal into an elongated staggered labyrinth seal type configuration possibly providing additional flow path restrictions. 


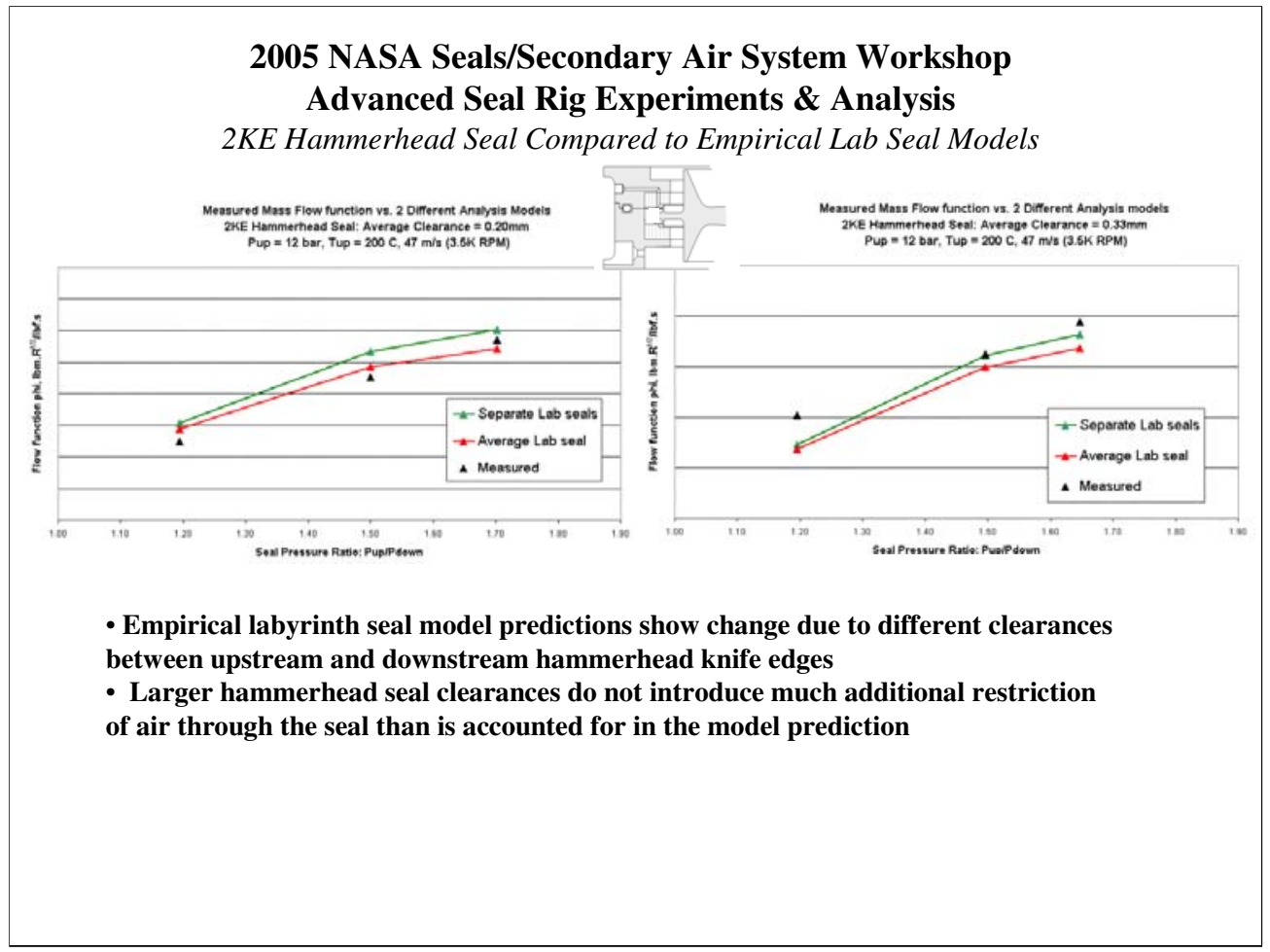

2KE Hammerhead Seal Compared to Empirical Lab Seal Models

Staggered restriction benefit with tight clearances is lost with the reduction in number of knife edges 


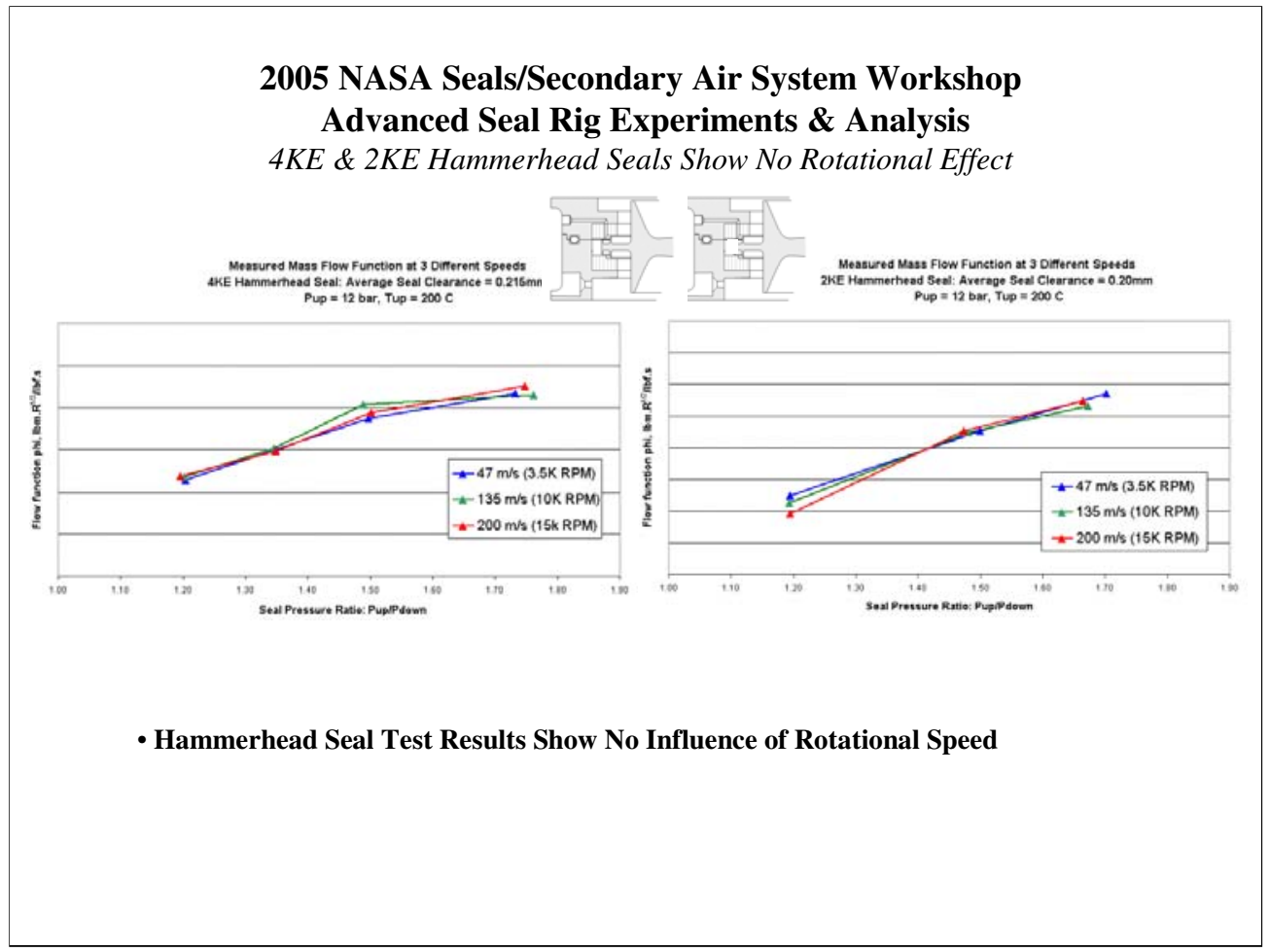

4KE \& 2KE Hammerhead Seals Show No Rotational Effect 


\section{NASA Seals/Secondary Air System Workshop Advanced Seal Rig Experiments \& Analysis}

4KE \& 2KE Hammerhead Seal Discharge Coefficient Comparison Matches Trend Predicted by CFD Models

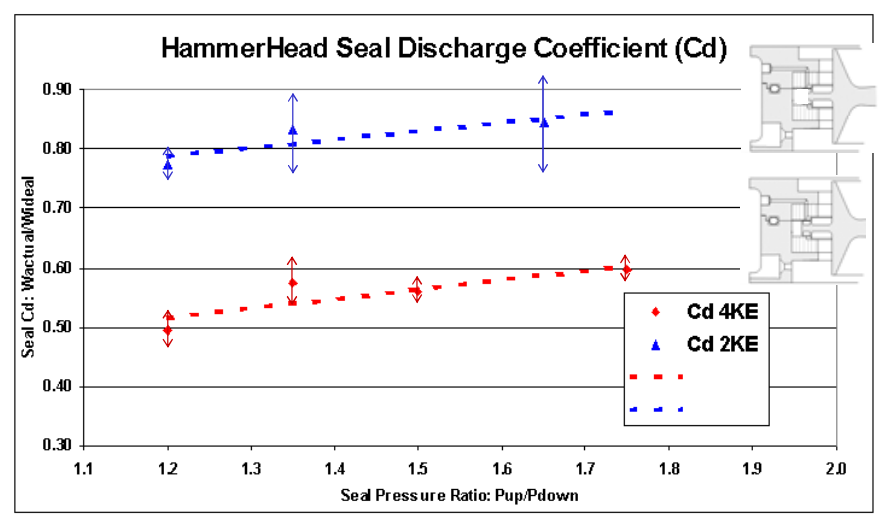

- Comparison of Discharge Coefficients Show that the 4KE Hammerhead Seal to be at least $25 \%$ more effective than the $2 \mathrm{KE}$ Seal

- These Results are in Line with the Hammerhead Seal Design CFD Sensitivity Studies (Trail 4 vs. Trial 9)

4KE \& 2KE Hammerhead Seal Discharge Coefficient Comparison Matches Trend Predicted by CFD Models

Arrows show data scatter but trend is still apparent. 


\section{NASA Seals/Secondary Air System Workshop Advanced Seal Rig Experiments \& Analysis \\ Conclusions/Future Work}

- CFD Modeling, Validated With Existing Rig Data, Used to Define New Seal Designs with Seal Reducing Features

- An Advanced Seal Rig is Available to Test Seals at Engine Operating Conditions - Phase 2 plan underway to extend rig capabilities to $365 \mathrm{~m} / \mathrm{s} \& 815^{\circ} \mathrm{C}$ by end of 2005

- Test Data Suggests that Concave Seal Flow is Reduced with Increasing Rotational Speed

- Additional testing at higher speeds planned

- A second canted seal design with seal angles reversed (with flow direction) planned

- 3D CFD analysis planned to investigate concave seal features providing rotation benefit; modeling of honeycomb cell structure will be included

- Empirical Labyrinth Seal Model Requires Updates for both Rotational and Axial Spacing Between Knife Edges and Steps

- Testing planned utilizing baseline validation seal for different axial spacings

- Test Data Shows that Hammerhead Seal Flow Does Not Change with Rotational Speed

- Hammerhead Seals are Basically a Compact Seal that Behaves Like a Labyrinth Seal; Seal Flow is Reduced with More Knife Edges and Steps Between Knife Edges

- Maintaining Tight Clearances Between the Hammerhead Seal and its Static Land Will Reduce Seal Flow by Forcing Air to Travel Through a More Tortuous Path 